\title{
Fostering Professionalism in Medical Education
}

\section{A Call for Improved Assessment and Meaningful Incentives}

\author{
William H. Shrank, MD, Virginia A. Reed, PhD, G. Christian Jernstedt, PhD
}

\begin{abstract}
Increasing attention has been focused on developing professionalism in medical school graduates. Unfortunately, the culture of academic medical centers and the behaviors that faculty model are often incongruent with our image of professionalism. The need for improved role modeling, better assessment of student behavior, and focused faculty development is reviewed. We propose that the incentive structure be adjusted to reward professional behavior in both students and faculty. The third-year medicine clerkship provides an ideal opportunity for clinician-educators to play a leading role in evaluating, rewarding, and ultimately fostering professionalism in medical school graduates.
\end{abstract}

KEY WORDS: professionalism; incentives; medical education; evaluation.

J GEN INTERN MED 2004;19:887-892.

$\mathbf{M}$ edical schools have long taught the technical aspects of medicine, but a focus on teaching the professional and healing qualities has been more recent. In 1998, Makoul and Curry discussed the evolution and future of medical school courses designed to teach professional skills and perspectives, with the goal of stimulating dialogue about ways to enhance the teaching of professionalism. ${ }^{1,2}$ In the present essay, our goal is to challenge medical educators to take a next step in that dialogue. Adjusting course curricula and improving awareness of professionalism represent a beginning; the next critical step is the assessment of professionalism and the construction of incentives that demonstrate that the profession truly values these qualities. It is our hope that the medical education community will engage in open dialogue about how to reconcile the gap between our aspirations and our current reality.

Received from the VA Greater Los Angeles Healthcare System (WHS); University of California Los Angeles School of Public Health (WHS), Los Angeles, Calif; The Center for Educational Outcomes at Dartmouth (VAR, GCJ); Dartmouth College (VAR, GCJ); and Dartmouth Medical School (VAR, GCJ), Hanover, NH.

Address correspondence and requests for reprints to Dr. Shrank: The VA Greater Los Angeles Healthcare System, Division of General Internal Medicine, 111G, 11301 Wilshire Boulevard Los Angeles, CA 90073 (e-mail: shrankw@aol.com).

\section{Learning Objectives for Medical Education}

The American Board of Internal Medicine (ABIM) has been a leader among the many professional societies and organizations that have explicitly addressed the need to promote professionalism in medicine. ${ }^{3-8}$ With Project Professionalism, the ABIM first undertook to define professionalism in the 1990s. Their widely adopted definition is broad and inclusive, composed of three commitments and six elements. The three commitments are to the highest standards of excellence in the practice of medicine, to sustain the interests and welfare of patients, and to be responsive to the health needs of society. The elements of professionalism as defined by the ABIM include altruism, accountability, excellence, honor, integrity, and respect for others, and are more fully described in Table $1 .^{9}$ This definition of professionalism is appropriately broad to include most all qualities and skills that are not knowledge based or technical in nature.

In 1998, the Association of American Medical Colleges (AAMC) published the Medical School Objectives Project (MSOP): Part I, a consensus statement formalizing four key attributes that graduating medical students should possess: altruism, knowledge, skill, and duty. ${ }^{10}$ In 1999 , the Accreditation Council on Graduate Medical Education (ACGME) endorsed six general competencies for residents: patient care, medical knowledge, practice-based learning and improvement, interpersonal and communication skills, professionalism, and systems-based practice. ${ }^{11}$ As of July 2002, successful development of these competencies became a requirement for residency programs. ${ }^{12}$ These organizations not only endorsed the need to foster and recognize professionalism in medical education, but laid out clear objectives for doing so.

Increasingly, medical schools have begun to emphasize the teaching of such qualities. Recent surveys show that nearly all U.S. medical schools include formal instruction in professionalism, ${ }^{13}$ often in a single course or in an integrated sequence of courses. ${ }^{14}$ While this is good news, it is only the beginning of a process that must be aimed at both expecting and requiring that our graduates demonstrate professionalism. Cohen has cautioned us to remember, "The quality of medical education must be evaluated by what it produces." ${ }^{15}$ Thus, next steps must move beyond process and focus on continuing to develop and refine 
Table 1. The Elements of Professionalism as Defined by the American Board of Internal Medicine

\begin{tabular}{|c|c|}
\hline \multirow{3}{*}{$\begin{array}{l}\text { Altruism } \\
\text { Accountability }\end{array}$} & The essence of professionalism, in which the best interest of the patients, not self-interest, is the rule. \\
\hline & To patients-honoring the patient/physician relationship. \\
\hline & To the profession-adhering to medicine's ethical precepts. \\
\hline Duty & $\begin{array}{l}\text { Free acceptance of a commitment to service (e.g., enduring unavoidable risks in the care of patients and } \\
\text { advocating best care regardless of ability to pay). }\end{array}$ \\
\hline Honor and integrity & $\begin{array}{l}\text { Consistent regard for the highest standards of behavior and the refusal to violate one's personal or } \\
\text { professional codes. }\end{array}$ \\
\hline
\end{tabular}

methods to assess outcomes and on compiling evidence about best practices aimed at achieving desired goals.

\section{The Need for Faculty Role Models}

Ludmerer has suggested that both formal teaching and role modeling are important to the development of professional values. ${ }^{16}$ In order for faculty to effectively model attitudes and attributes for students, they must hold these same characteristics and values for themselves. Here we face a major obstacle in delivering change: our actions must be congruent with our rhetoric. Despite institutional efforts to improve professionalism, medical students often receive mixed messages. On the one hand, schools are increasingly teaching about the importance of professionalism. On the other hand, students regularly observe unprofessional behavior. In a study of students at six medical schools, 98\% of students reported hearing instructing physicians speak in a derogatory manner about their patients while on the wards and $61 \%$ of students reported seeing team members engage in behavior the students deemed unethical. ${ }^{17}$

Hafferty has suggested that the informal and hidden curricula, which emphasize the importance of informal interpersonal interactions and the influence of organizational structure and culture on the education process, greatly influence student learning and often are counter to the formal curriculum. ${ }^{18,19}$ Similarly, Stern found that medical students received a disproportionate amount of their training in professional values from the informal curriculum and that those values were often in direct conflict with those espoused by the formal curriculum. ${ }^{20}$

Faculty development with an eye toward role modeling is a key component of the effort to promote professionalism. Preston pointed out that medical education has historically relied on a community of physicians with shared values. ${ }^{21}$ In this community, students' interactions with faculty have exposed them to these values and, hence, have been crucial to student learning and adoption of these values. If many of the values being transmitted to students are inappropriate, the medical education community must work to clarify, reassert, explicitly state, and model the appropriate values as standards.

Further, the community must find ways to provide faculty with information concerning their own performance relative to the standards. In his work on motivational effects, Bandura asserted that both knowledge of standards and knowledge of one's own performance are required to change behavior through self-evaluative mechanisms. ${ }^{22}$ One alternative would be to emphasize student, peer, and self-evaluation of professionalism of faculty members. By expanding the evaluation pool, we may encourage more faculty awareness and concern for professional behavior. Recognizing the power of informal interactions, explicitly acknowledging professional values standards, and incorporating the evaluation of performance against these standards into self and peer review processes are ways of helping faculty further develop these values in themselves and model them to others.

\section{Improving Student Assessment}

Meaningful, accurate student assessment with feedback is crucial to fostering professionalism in medical students. Unfortunately, many current assessment practices are not optimal. The ABIM has opined that humanism can most realistically be assessed by direct observation. ${ }^{23}$ But, with time-strapped clinicians evaluating students in clinical clerkships, direct observation of students in the clinical environment is a rarity. ${ }^{24}$ When observation does occur, one study found that faculty were hesitant and, in most cases, unwilling to confront learners exhibiting what they perceived to be disrespectful, hostile, or uncaring behaviors toward patients. ${ }^{25}$ Faculty admitted they were uncomfortable providing negative feedback, were not prepared to do so, and felt ill at ease imposing what they perceived to be their own standards and values on others. If our goal is to foster professionalism in training physicians, faculty must have time to observe students in clinical scenarios and must receive training that allows them to accurately assess student behaviors and provide effective, evaluative feedback. A recent study of associate deans responsible for medical schools' curricula found that $97 \%$ requested faculty development materials. ${ }^{14}$ Skills needed to provide effective feedback are among those that have been identified as important targets of several faculty development programs. $^{26,27}$

When student professionalism is assessed, it is often assessed inadequately. The most common assessment method is the global performance rating, in which the 
evaluator retrospectively rates general categories of behavior using a numerical scale. ${ }^{28}$ In practice, the global performance rating strategy has been shown to contain significant flaws, including leniency error ${ }^{29}$ and a paucity of specific written comments. ${ }^{30}$ Some have argued that the lack of direct observation and the unreliability of raters' memories lead to "little more than a popularity contest." 31 The ACGME has noted that use of focused evaluation, based on particular encounters or tasks, is needed to improve assessment. $^{32}$

\section{Tools for Assessing Professionalism}

A number of approaches to more accurate assessment of professionalism have been suggested. The use of objective structured clinical exams (OSCEs) and simulated patientbased assessment has been shown to decrease some of the variability of ratings by providing a more stable and objective venue for assessment. ${ }^{33}$ Such methodologies are increasingly being utilized to assess qualities ranging from communication skills to cultural sensitivity. ${ }^{34-36}$ OSCEs have been shown to provide reliable and valid assessments of students' humanism, ${ }^{37}$ communication, ${ }^{34,38}$ and empathy. ${ }^{39}$ In 2005, the United States Medical Licensing Examination will include a multistation OSCE designed to assess communication skills. Successful performance on the OSCE will be required to obtain medical licensure. ${ }^{40}$

Another method that has been gathering support is student peer review. ${ }^{41}$ Peer evaluations have the potential to add value to the importance of teamwork and help train students in evaluation and feedback skills. Early studies have demonstrated evidence of reliability and validity in peer assessment in medical students. ${ }^{42}$ Peer evaluations have been shown to offer useful insight into learners' interpersonal skills ${ }^{43}$ and professional behavior. ${ }^{44}$ While students in one study expressed concern about their ability to be objective when evaluating peers and about how such a process could impact personal relationships, the study also reported that students generally found both sides of the process useful and that students were enthusiastic about participating. ${ }^{45}$

Another approach to evaluating professionalism requires an expansion of the evaluator pool. The 360-degree evaluation has been suggested by the ACGME as a way of providing feedback from multiple sources in a student's sphere of influence in the clinical setting. ${ }^{28}$ Evaluators may include patients, nursing staff, and peers, as well as faculty and house staff, who provide feedback on the learner's performance. While this assessment method may be cumbersome to administer, it is likely that students would benefit by becoming more aware of, and taking more pride in, the quality of interactions with all participants involved in the care of a patient. Three hundred sixty-degree assessments have been shown to be effective in a number of organizational environments outside of medicine. ${ }^{46,47}$ A recent study of this approach in physical medicine and rehabilitation residents indicated instrument reliability and reproducibility, and concluded that the approach was useful in providing formative feedback to residents regarding professionalism. ${ }^{48}$

Other, more creative approaches for assessing professionalism have been proposed. For example, Minsch has suggested that medical schools develop qualitative measures utilizing humanism "connoisseurs" who possess expertise in the interpersonal components of the medical art. ${ }^{49}$ Other innovations take advantage of recent technological advances. For example, the "virtual practicum" was developed to provide a simulation that mirrors the realism and complexity found in practice and that focuses on difficult ethical situations and communication dilemmas. ${ }^{50}$ A number of medical educators have suggested that reflection can be another useful method for making professional and humanistic qualities more clinically salient for students. ${ }^{51-53}$ While these approaches require further study to determine their effectiveness, they represent new, creative strategies for assessing professionalism in medical students.

Unfortunately, as yet, there are no proven best practices for assessing professionalism. In a recent, exhaustive review of the assessment of professionalism, Arnold concluded that, while there is a rich array of assessment tools available, no single tool is adequate and multiple sources ought to be used to assess professionalism. ${ }^{54}$ The ACGME and the ABIM both agree that multiple methods and evaluators should be used to increase the reliability and validity of assessments. ${ }^{55,56}$ As the field of evaluating professionalism matures, there is little question that more direct observation and a more concerted effort toward honest assessment and feedback will move our profession closer to the ultimate goal of reliably evaluating students' professional qualities. More study is needed to test the validity and reliability of measures to assess professionalism.

\section{Real Incentives to Behave Professionally}

If we want professional behavior to increase-on the part of either students or faculty-we need to provide real incentives for such change. Currently, medical education is predominantly geared to reward academic achievement. Students find that their acceptance into a desirable residency program is dependent, in large part, on their medical school grades and rankings. Thus, the grading system continues to be the mechanism by which medical students are rewarded for good work and, as such, "good grades" define "good work." In general, performance in the third-year clinical clerkships receives much more emphasis than performance in the preclinical years. Professionalism evaluations in the third year often are comprised of a general measure of professional behavior, or a global rating scale, ${ }^{57}$ without explicit weights or values. Given the nature of such evaluations, it is likely that students' perceptions of the association between their professional behavior and their overall grade in a clerkship are not always clear.

Some schools are beginning to develop policies and mechanisms for formally identifying and working with students who display unprofessional behavior. The University 
of California, San Francisco, School of Medicine has developed such a system. ${ }^{58}$ By including interpersonal skills as a specific area in which clerkship students are evaluated and, if found lacking, are remediated and counseled, the system designers have begun to change the reward structure and, hence, the value system. Another example is Brown University School of Medicine, which has implemented a competency-based curriculum that defines nine abilities, including effective communication, in which a student must be certified in order to graduate. ${ }^{59}$ By making competency in this area a program requirement, the curriculum designers have indicated to students the degree to which they value communication skills, an important component of professionalism. The impact of such programs on student attitudes and behavior remains to be seen, but recognition of the need and implementation of programs designed to meet the need are important first steps.

It is not enough to evaluate professionalism as a minimum standard that must be hurdled in order for promotion. Clear, formal, feedback mechanisms with visible rewards for excellence in professionalism are needed to significantly impact behavior. The need for positive reinforcement and effective feedback has long been acknowledged as integral to the learning process. ${ }^{60}$ Providing incentives for specific behavior is a very potent way to reinforce that behavior. Since the seminal research by Skinner, a large body of evidence has been amassed which demonstrates that learners preferentially perform behaviors when rewards are present for them. ${ }^{61,62}$

We suggest an explicit grade in professionalism in the clinical clerkships that could reinforce the value of professionalism and provide incentive for students to take pride in professional behavior. Clerkship directors often break down the grading system for clerkships and assign weights to clerkship evaluations and written tests. An explicit weight for professionalism evaluations, a carved-out portion of the evaluation, could help foster the behaviors that the profession deems important.

Some might argue that creating an explicit grade for professionalism seems inherently paradoxical, that assigning external rewards for altruistic behavior diminishes the level of altruism in the behavior. It would be ideal if the medical community, left to its own devices, would exhibit professionalism, and no external rewards would be necessary. But, if the medical community deems that there is a problem, creating positive feedback for desirable behavior could lead to the most rapid adoption of desired behaviors.

It is plausible that explicit evaluations of professionalism may also impact faculty behavior, and, as such, formal changes in the curriculum may influence the informal and hidden curricula. As Maudsley noted, the content and process of student assessment determine what is perceived to be of value in the educational process for both students and faculty. ${ }^{63}$ One could surmise that explicit evaluations of medical student behavior may influence evaluators to be more aware of their own behavior and may contribute to an environment in which there is more congruence between the stated goals for professional behavior and the behaviors role modeled for medical students. As medical educators implement and evaluate student assessment strategies to improve professionalism, it is important to also evaluate the extent to which variations in the assessment process may also lead evaluators to be more aware of their own professionalism and to behave more professionally.

There are at least two tangible ways to reward faculty who model exemplary professional and humanistic behavior. One is through awards such as the national humanism in medicine awards given by the AAMC, the Arnold P. Gold Foundation, and the Healthcare Foundation of New Jersey. ${ }^{64-66}$ On the local level, some medical schools use awards to recognize faculty members who demonstrate outstanding professional or humanistic behavior. Another, more universally accessible reward would be the provision of some type of educational relative value units (RVUs) that count toward promotion and are given for excellent rolemodeling behavior. Development of educational RVUs would require medical schools to make a significant financial investment in fostering professionalism. A national panel on medical education appointed by the AAMC recently developed a "metrics system for measuring medical school faculty effort and contributions to a school's education mission," including a four-step process to create RVUs for education activities. ${ }^{67}$ Additional study is necessary to develop systems of measuring and rewarding high-quality professionalism role modeling among educators.

Third-year medical student clerkships in medicine provide an opportunity for internists and medical subspecialists to continue to pioneer the promotion of professionalism in our medical students. Students experience a great deal of patient contact during their medicine clerkships, allowing ample opportunity for observation, evaluation, and feedback. Whatever the discipline in which students plan a career, excellent performance in the medicine clerkship is invaluable toward achieving their goals. It is during the medicine clerkship that internists and medical subspecialists have the opportunity to formally move professionalism into the forefront. By creating a clear link between professional behavior and rewards, we can encourage students and faculty to take more pride in the art of communication, empathy, and caring.

\section{Making the Goals of Reform a Reality}

The reform goals that have been laid out by MSOP and others call for major change in the U.S. medical education system. System-wide success requires the medical education community to engage in dialogue about how to adjust the formal as well as the informal curricula and to be aware of the connectedness of both. If we are serious about the goal, we must move beyond rhetoric. We must find accurate ways to assess professionalism in both students and faculty. We must also change the incentive system so that rewards adequately reflect the characteristics and behaviors that are deemed important. At the same time, we must 
increasingly hold ourselves accountable for modeling the attitudes and behaviors we desire to instill in our students. Only then can we move forward intentionally, designing processes and systems that will create and support the future we envision.

We would like to thank Dr. C. Everett Koop for his assistance, support, and direction in this project.

Funding for this project was provided in part by the C. Everett Koop Institute at Dartmouth, where Dr. Shrank was previously a fellow.

\section{REFERENCES}

1. Curry RH, Makoul G. The evolution of courses in professional skills and perspectives for medical students. Acad Med. 1998;73:10-3.

2. Makoul G, Curry RH, Novack DH. The future of medical school courses in professional skills and perspectives. Acad Med. 1998;73:48-51.

3. American Board of Internal Medicine. Project Professionalism; 1995. Available at: http://www.abim.org/pubs/profess.pdf Accessed May 28, 2003.

4. ABIM Foundation. Professionalism. Available at: http:// www.abimfoundation.org/professional.html. Accessed May 28, 2003

5. American Board of Pediatrics. Professionalism. Available at: http:// www.abp.org/resident $\neq$ profguid.htm. Accessed May 23, 2003.

6. Society for Academic Emergency Medicine. An argument for professionalism. Available at: http://www.saem.org/inform/ adams.htm. Accessed May 23, 2003.

7. Howard University College of Medicine, American College of Chest Physicians, and the CHEST Foundation, Washington, DC. Overcoming disparities in health care: a national dialogue facilitated by the surgeons general. April 9, 2003. Available at: http://www.kaisernetwork.org / health_cast/hcast_index.cfm?display=detail\&hc=829. Accessed June 19, 2003.

8. American Academy of Orthopaedic Surgeons. Principles of medical ethics and professionalism in orthopaedic surgery. Available at: http://www.aaos.org/wordhtml/papers/ethics/prin.htm. Accessed May 23, 2003.

9. American Board of Internal Medicine. American professionalism in medicine: issues and opportunities. Definition and objectives Available at: http://www.abim.org/pubs/p2/definitn.htm. Accessed October 15, 2003.

10. Medical School Objectives Writing Group. Report I: learning objectives for medical student education. Acad Med. 1999;74:13-8.

11. Accreditation Council on Graduate Medical Education. ACGME Outcome project slides. Available at: http://www.acgme.org/outcome/ project/OutIntro.htm. Accessed May 28, 2003.

12. Accreditation Council on Graduate Medical Education. ACGME Outcome project timeline. Available at: http://www.acgme.org/ outcome/project/timeline.asp. Accessed May 28, 2003.

13. Swick HM, Szenas P, Danoff D, Whitcomb ME. Teaching professionalism in undergraduate medical education. JAMA. 1999;282:830-

14. Kao A, Lim M, Spevick J, Barzansky B. Teaching and evaluating school's professionalism in US medical schools, 2002-2003. JAMA 2003;290:1151-2.

15. Cohen JJ. Leadership for medicine's promising future. Acad Med 1998;73:132-7.

16. Ludmerer KM. Instilling professionalism in medical education. JAMA. 1999;282:881-2.

17. Feudtner C, Christakis DA, Christakis NA. Do clinical clerks suffer ethical erosion? Students' perceptions of their ethical environment and personal development. Acad Med. 1994;69:670-9.

18. Hafferty FW, Franks R. The hidden curriculum, ethics teaching, and the structure of medical education. Acad Med. 1994;69:86171.

19. Hafferty FW. Beyond curriculum reform: confronting medicine's hidden curriculum. Acad Med. 1998;73:403-7.

20. Stern DT. In search of the informal curriculum: when and where professional values are taught. Acad Med. 1998;73(10 suppl):S28S30.

21. Preston R. Reaffirming professionalism through the education community. Ann Intern Med. 1994;120:609-14.

22. Bandura A. Social Foundations of Thought and Action: A Social Cognitive Theory. Englewood Cliffs, NJ: Prentice-Hall, Inc.; 1986.

23. American Board of Internal Medicine. A Guide to Awareness and Evaluation of Humanistic Qualities in the Internist. Philadelphia, Pa: American Board of Internal Medicine; 1985.

24. Barrows HS. An overview of the uses of standardized patients for teaching and evaluating clinical skills. Acad Med. 1993;68:443-51.

25. Burack JH, Irby DM, Carline JD, Root RK, Larson EB. Teaching compassion and respect: attending physicians' responses to problematic behaviors. J Gen Intern Med. 1999;14:49-55.

26. Richards BF, Wilking AP, Kirkland R. A four-month faculty development curriculum on teaching and learning. Acad Med. 1999;74:614-5.

27. Hewson MG. A theory-based faculty development program for clinician-educators. Acad Med. 2000;75:498-501.

28. Accreditation Council of Graduate Medical Education and American Board of Medical Specialties Joint Initiative. Toolbox of Assessment Methods. Version 1.1, September 2000.

29. Kreiter CD, Ferguson K, Lee WC, Brennan RL, Densen P. A generalizability study of a new standardized rating form used to evaluate students' clinical clerkship performances. Acad Med. 1998;73:1294-8.

30. Littlefield $\mathrm{J}$, Terrel C. Improving the quality of resident performance appraisals. Acad Med. 1997;72(suppl 1):S45-S47.

31. Cunnington JPW, Neville AJ, Norman GR. The risks of thoroughness: reliability and validity of global ratings and checklists in an OSCE. Adv Health Sci Educ. 1997;1:227-33.

32. Swing S. The ACGME Outcome Project: Where are we now? Where are we going? Plenary session presented at the 33rd Annual Meeting of the Association for the Behavioral Sciences and Medical Education, Charleston, SC, October 10, 2003.

33. Roberts J, Norman G. Reliability and learning from the objective structured clinical examination. Med Educ. 1990;24:219-23.

34. Hodges B, Turnbull J, Cohen R, Bienenstock A, Norman G. Evaluating communication skills in the OSCE format: reliability and generalizability. Med Educ. 1996;30:38-43.

35. Roberts C, Wass V, Jones R, Sarangi S, Gillet A. A discourse analysis study of 'good' and 'poor' communication in an OSCE: a proposed new framework for teaching students. Med Educ. 2003;37:186-7.

36. Altshuler L, Kachur E. A culture OSCE: teaching residents to bridge different worlds. Acad Med. 2001;76:514.

37. Rogers JC, Coutts L. Do students' attitudes during preclinical years predict their humanism as clerkship students? Acad Med. 2000;75(10 suppl):S74-S77.

38. Pieters HM, Touw-Otten FW, DeMelker RA. Simulated patients in assessing consultation skills of trainees in general practice vocational training: a validity study. Med Educ. 1994;38:226-33.

39. Schnabl GK, Hassard TH, Kopelow ML. The assessment of interpersonal skills using standardized patients. Acad Med. 1991;66(9 suppl):S34-S36.

40. United States Medical Licensing Examination. Americans overwhelmingly support new medical license test; field trials show fairness, reliability of test. Available at: http://www.usmle.org/ news/cse/newsrelease2503.htm. Accessed May 22, 2003.

41. Freedman JA, Lehmann HP, Ogborn CJ. Web-based peer evaluation by medical students. Acad Med. 2000;75:539-40.

42. Arnold L, Willoughby L, Calkins V, Gammon L, Eberhart G. Use of peer evaluation in the assessment of medical students. J Med Educ. 1981;56:35-42. 
43. Helfer RE. Peer evaluation: its potential usefulness in medical education. Br J Med Educ. 1972;6:224-31.

44. Small PA Jr, Stevens B, Duerson MC. Issues in medical education: basic problems and potential solutions. Acad Med. 1993;68(10 suppl):S89-S93.

45. Asch E, Saltzberg D, Kaiser S. Reinforcement of self-directed learning and the development of professional attitudes through peer- and self-assessment. Acad Med. 1998;73:575.

46. Facteau CL, Facteau JD, Schoel LC, Russell JEA, Poteet ML. Reactions of leaders to 360-degree feedback from subordinates and peers. Leadership Q. 1998;9:427-48.

47. Antonioni D. Designing an effective 360-degree appraisal feedback process. Organ Dyn. 1996;25:24-38.

48. Musick DW, McDowell SM, Clark N, Salcido R. Pilot study of a 360-degree assessment instrument for physical medicine and rehabilitation residency programs. Am J Phys Med Rehabil. 2003;82:394-402.

49. Minsch, DA. Evaluating physicians' professionalism and humanism: the case for humanism "connoisseurs." Acad Med. 2002;77:489-95.

50. Henderson JV. Comprehensive, technology-based clinical education: the "virtual practicum." Int J Psych Med. 1998;28:41-79.

51. Branch WT, Paranjape A. Feedback and reflection: teaching methods for clinical settings. Acad Med. 2002;77:1185-8.

52. Gordon J. Assessing students' personal and professional development using portfolios and interviews. Med Educ. 2003;37:335-40.

53. Baernstein A, Fryer-Edwards K. Promoting reflection on professionalism: a comparison trial of educational interventions for medical students. Acad Med. 2003;78:742-7.

54. Arnold L. Assessing professional behavior: yesterday, today and tomorrow. Acad Med. 2002;77:502-15.

55. Accreditation Council on Graduate Medical Education. Key considerations for selecting assessment instruments and implementing assessment systems. Available at: http://www.acgme.org/outcome/ assess/keyConsider.asp. Accessed October 15, 2003.
56. American Board of Internal Medicine. Strategies for evaluating professionalism. Available at: http://www.abim.org/pubs/p2/ strategy.htm. Accessed October 15, 2003.

57. Arnold E, Blank L, Race K, Cipparone N. Can professionalism be measured? The development of a scale to be used in the medical environment. Acad Med. 1998;73:1119-21.

58. Papadakis MA, Osborn EHS, Cooke M, Healy K. University of California, San Francisco, School of Medicine Clinical Clerkships Operation Committee. A strategy for the detection and evaluation of unprofessional behavior in medical students. Acad Med. 1999;74:980-90.

59. Smith S. An Educational Blueprint for the Brown University School of Medicine: Competency-based Curriculum. 3rd ed. Providence, RI: Brown University School of Medicine; 1997.

60. Sachdeva AK. Use of effective feedback to facilitate adult learning. J Cancer Educ. 1996;11:106-18.

61. Skinner BF. Science and Human Behavior. New York, NY: Macmillan; 1953.

62. Weirsma UJ. The effects of extrinsic rewards in intrinsic motivation: a meta-analysis. J Occup Organ Psychol. 1992;65:101-14.

63. Maudsley RF. Content in context: medical education and society's needs. Acad Med. 1999;74:143-5.

64. Association of American Medical Colleges. Humanism in Medicine Award. Available at: http://www.aamc.org/about/awards/ humanism.htm. Accessed May 22, 2003.

65. Arnold P. Gold Foundation. Humanism in Medicine Awards. Available at: http://www.humanism-in-medicine.org/. Accessed May 22, 2003.

66. Healthcare Foundation of New Jersey. HFNJ Humanism in Medicine Awards. Available at: http://hfnj.org/patient.htm. Accessed May $22,2003$.

67. Nutter DO, Bond JS, Coller BS, et al. Measuring faculty effort and contributions in medical education. Acad Med. 2000;75:199207. 